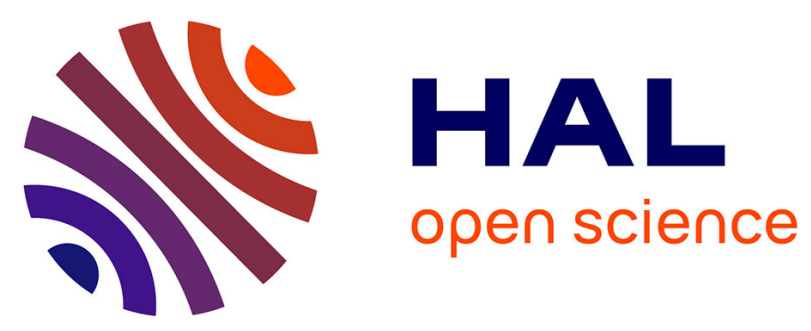

\title{
Dissipation and adsorption of isoproturon, tebuconazole, chlorpyrifos and their main transformation products under laboratory and field conditions
}

\author{
Evangelia S. Papadopoulou, Panagiotis A. Karas, Sofia Nikolaki, Véronika
}

Storck, Federico Ferrari, Marco Trevisan, George Tsiamis, Fabrice

Martin-Laurent, Dimitrios G. Karpouzas

\section{To cite this version:}

Evangelia S. Papadopoulou, Panagiotis A. Karas, Sofia Nikolaki, Véronika Storck, Federico Ferrari, et al.. Dissipation and adsorption of isoproturon, tebuconazole, chlorpyrifos and their main transformation products under laboratory and field conditions. Science of the Total Environment, 2016, 569, pp.86-96. 10.1016/j.scitotenv.2016.06.133 . hal-01605004

\section{HAL Id: hal-01605004 https://hal.science/hal-01605004}

Submitted on 28 May 2020

HAL is a multi-disciplinary open access archive for the deposit and dissemination of scientific research documents, whether they are published or not. The documents may come from teaching and research institutions in France or abroad, or from public or private research centers.
L'archive ouverte pluridisciplinaire HAL, est destinée au dépôt et à la diffusion de documents scientifiques de niveau recherche, publiés ou non, émanant des établissements d'enseignement et de recherche français ou étrangers, des laboratoires publics ou privés. 


\title{
Dissipation and adsorption of isoproturon, tebuconazole, chlorpyrifos and their main transformation products under laboratory and field conditions
}

\author{
Evangelia S. Papadopoulou ${ }^{\text {a,b }}$, Panagiotis A. Karas ${ }^{\text {a,b }}$, Sofia Nikolaki ${ }^{\text {b,c }}$, Veronika Storck ${ }^{\text {b,d }}$, Federico Ferrari ${ }^{\text {b }}$, \\ Marco Trevisan ${ }^{\mathrm{e}}$, George Tsiamis ${ }^{\mathrm{c}}$, Fabrice Martin-Laurent ${ }^{\mathrm{d}}$, Dimitrios G. Karpouzas ${ }^{\mathrm{a}, *}$ \\ a University of Thessaly, Department of Biochemistry and Biotechnology, Laboratory of Plant and Environmental Biotechnology, Larisa, Greece \\ ${ }^{\mathrm{b}}$ Aeiforia srl, Spinoff Università Cattolica del Sacro Cuore, Fidenza, Italy \\ c University of Patras, Department of Environmental and Natural Resources Management, Agrinio, Greece \\ d INRA, UMR 1347 Agroécologie, Dijon, France \\ e Università Cattolica del Sacro Cuore, Instituto di Chimica Agraria ed Ambientale, Piacenza, Italy
}

\section{H I G H L I G H T S}

- The environmental fate of 3 pesticides was evaluated via a lab-to-field approach.

- Lab and field persistence increased in the order $\mathrm{IPU}<\mathrm{CHL}<\mathrm{TCZ}$.

- IPU was demethylated and CHL was hydrolyzed.

- Adsorption of parent compounds increased as $\mathrm{IPU}<\mathrm{TCZ}<\mathrm{CHL}$.

- Transformation products showed low adsorption affinity except 4-IA.

\section{A R T I C L E I N F O}

\section{Article history:}

Received 19 May 2016

Received in revised form 17 June 2016

Accepted 17 June 2016

Available online 21 June 2016

Editor: D. Barcelo

Keywords:

Isoproturon
G R A P H I C A L A B S T R A C T

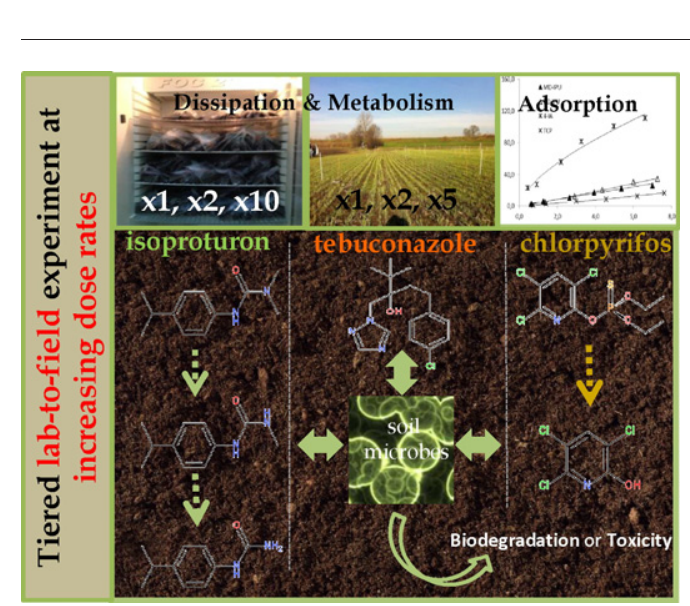

\section{A B S T R A C T}

Assessment of dissipation constitutes an integral part of pesticides risk assessment since it provides an estimate of the level and the duration of exposure of the terrestrial ecosystem to pesticides. Within the frame of an overall assessment of the soil microbial toxicity of pesticides, we investigated the dissipation of a range of dose rates of three model pesticides, isoproturon (IPU), tebuconazole (TCZ), and chlorpyrifos (CHL), and the formation and dissipation of their main transformation products following a tiered lab-to-field approach. The adsorption of pesticides and their transformation products was also determined. IPU was the least persistent pesticide showing a dose-dependent increase in its persistence in both laboratory and field studies. CHL dissipation showed a dosedependent increase under laboratory conditions and an exact opposite trend in the field. TCZ was the most persistent pesticide under lab conditions showing a dose-dependent decrease in its dissipation, whereas in the field

\footnotetext{
Abbreviations: IPU, isoproturon; TCZ, tebuconazole; CHL, chlorpyrifos; MD-IPU, monodesmethyl-isoproturon; DD-IPU, didesmethyl-isoproturon; 4-IA, 4-isopropylaniline; TCP, 3,5,6trichloro-2-pyridinol.

* Corresponding author.

E-mail address: dkarpouzas@bio.uth.gr (D.G. Karpouzas).
} 
Tebuconazole Chlorpyrifos Dissipation Adsorption

Lab-to-field assessment
TCZ exhibited a biphasic dissipation pattern with extrapolated $\mathrm{DT}_{90 \text { s }}$ ranging from 198 to 603.4 days in the $\times 1$ and $\times 2$ dose rates, respectively. IPU was demethylated to mono- (MD-IPU) and di-desmethyl-isoproturon (DD-IPU) which dissipated following a similar pattern with the parent compound. CHL was hydrolyzed to 3,5,6-trichloro-2-pyridinol (TCP) which dissipated showing a reverse dose-dependent pattern compared to CHL. Pesticides adsorption affinity increased in the order IPU $<\mathrm{TCZ}<\mathrm{CHL}$. IPU transformation products showed low affinity for soil adsorption, whereas TCP was weakly adsorbed compared to its parent compound. The temporal dissipation patterns of the pesticides and their transformation products will be used as exposure inputs for assessment of their soil microbial toxicity.

(C) 2016 Published by Elsevier B.V.

\section{Introduction}

Pesticides still constitute an integral part of modern agriculture despite the environmental and health risks associated with their use (Muñoz-Leoz et al., 2011). Upon their application, either intentionally or unintentionally, they reach the soil environment which acts as a sink for their further distribution to other environmental compartments depending on their soil dissipation rates (Arias-Estévez et al., 2008). Thus, good knowledge of the dissipation and metabolism of pesticides in soil is an essential part of risk assessment since it determines the scenario of exposure of the soil ecosystem. The level and the duration of exposure has to be known in order to assess the toxicity of pesticides to non-target soil organisms including microorganisms, which have been identified by the European Food Safety Agency as one of the specific protection goals (EFSA, 2010). Recently, Martin-Laurent et al. (2013), proposed a revision in the regulatory framework regarding the assessment of the soil microbial toxicity of pesticides. This involves the implementation of a tiered lab-to-field experimental approach where the dissipation and transformation of the studied pesticides (measure of exposure) coupled with standardized advanced biochemical and molecular methods (measure of toxicity) could provide a more robust estimation of the soil microbial toxicity of pesticides (Karpouzas et al., 2014). Within this framework, we studied the dissipation and the transformation of a range of dose rates of three model pesticides; isoproturon (IPU), tebuconazole (TCZ), and chlorpyrifos ( $\mathrm{CHL}$ ) which were chosen based on their widespread use in Europe.

IPU [3-(4-isopro-pylphenyl)-1,1-dimethylurea] is a phenylurea herbicide used for the control of annual grasses and broad-leaved weeds in spring and winter cereals (Collings et al., 2003). It shows variable persistence in soil with $\mathrm{DT}_{50}$ values varying from 3 to 200 days (Alletto et al., 2006). Its extensive use has resulted in its common detection in surface and groundwater resources (Skark and Zullei-Seibert, 1995; Skark et al., 2004). Mono-desmethyl-isoproturon [3-(4-isopropylphenyl)-1methylurea (MD-IPU), di-desmethyl-isoproturon [3-(4-phenyl)-urea] (DD-IPU), 4-isopropyl-aniline (4-IA) and several hydroxylated compounds (Lehr et al., 1996; EFSA, 2015) have been identified as the most common transformation products of IPU in soil. Some of these have been found to exert higher toxicity than the parent compound (Hussain et al., 2015; Alletto et al., 2006; Tixier et al., 2002). However, little is known regarding their dissipation kinetics and adsorption in soil.

TCZ [(RS)-1-p-chlorophenyl-4,4-dimethyl-3-(1H-1,2,4-triazol-1-yl methyl)pentan-3-ol] is a systemic triazole fungicide which is used for the control of a range of plant fungal pathogens in different crops including winter cereals (D'Angelo et al., 2014; Keinath, 2015). It is rather persistent in the soil environment with $\mathrm{DT}_{50 \text { s }}$ ranging from 49 to 610 days (Strickland et al., 2004; EFSA, 2014). Monitoring studies in agricultural areas where $\mathrm{TCZ}$ is used have verified its frequent presence in surface and groundwater systems (Herrero-Hernández et al., 2013; Sancez-Gonzalez et al., 2013). Although its dissipation and transformation in soil has been studied previously (Álvarez-Martín et al., 2016; Herrero-Hernández et al., 2013; Potter et al., 2005; Strickland et al., 2004), little is known regarding the fate of its transformation products in the environment (Storck et al., 2016).

CHL [0,0-diethyl 0-3,5,6-trichloro-2-pyridinyl phosphorothioate] is one of the most extensively used organophosphate insecticides with a broad spectrum of activity (Joseph and Zarate, 2015). Its degradation in soil proceeds mainly via hydrolysis, abiotic and biotic, with $\mathrm{DT}_{50}$ values ranging from 10 to 120 days (Racke, 1993). Hydrolysis of CHL leads to the formation of 3,5,6-trichloro-2-pyridinol (TCP) which is known to have adverse effects on soil microbial activity and on the degradation of the parent compound (Racke et al., 1990). However, to date limited knowledge is available regarding the dissipation and adsorption of TCP in agricultural soils where CHL has been applied.

The main objectives of the present study were a) to determine the dissipation of the three model-pesticides applied to soil at different dose rates under laboratory $(\times 1, \times 2$ and $\times 10$ the recommended dose rate) and field conditions $(\times 1, \times 2$ and $\times 5$ the recommended dose rate), b) to follow the dynamics of formation and dissipation of the main transformation products of the model pesticides and c) to determine the soil adsorption affinity of the model pesticides and their main transformation products. This will provide a thorough view of the soil persistence of the studied pesticides and their transformation products which defines the scenario of exposure of non-target soil organisms to be taken into account to estimate potential toxicity risks in follow up studies.

\section{Materials and methods}

\subsection{Pesticides}

Analytical standards of IPU (99.9\%), MD-IPU (99.5\%), DD-IPU (99.0\%), TCZ (98.8\%), CHL (97\%), and TCP (99.0\%) were purchased by Dr. Ehrenstorfer, (Germany). The analytical standard of 4-IA (99.0\%) was purchased by Sigma-Aldrich (Germany). Commercial formulations of IPU (QUINTIL® 500SC), TCZ (FOLICUR 25SE) and CHL (CARPOSAN 48EC), were provided by Phytorus (http://www.phytorus.eu/en/), Bayer CropScience (Germany) and ISAGRO (Italy), respectively.

\subsection{Microcosm experiment}

The soil used was collected in July 2013 from a field site situated in North Italy (area of Mortizza, 45 $05^{\prime} 20.8^{\prime \prime} \mathrm{N} 9^{\circ} 45^{\prime} 59.4^{\prime \prime} \mathrm{E}$ (Google Maps) which was also used for the execution of the field experiment described below. The physicochemical characteristics of the soil are shown in Supplementary Data Table 1. The field site did not have a recent history of treatment with IPU, TCZ, and CHL. Topsoil samples $(0-10 \mathrm{~cm}$ depth) were collected from the field site following the W non-systematic pattern of sampling, according to ISO 10381-1 and -2 guidelines (2002), and mixed thoroughly to provide a single bulk soil sample. The soil was then partially air-dried, sieved to pass through a $2 \mathrm{~mm}$ mesh sieve and divided into 10 subsamples ( $6 \mathrm{~kg}$ each). For each pesticide, three subsamples were treated with appropriate amounts of aqueous solutions of IPU, TCZ and CHL (prepared from their commercial formulations) aiming to the application of $\times 1, \times 2$ and $\times 10$ the recommended dose rates (Supplementary Data Table 2). The final soil subsample received the same amount of water without pesticide to serve as non-treated control. After pesticide application the soils were left to equilibrate for $1 \mathrm{~h}$ and water was added to adjust moisture to $40 \%$ of the water holding capacity. Soil samples were separated into 150 -g subsamples which were placed in aerated plastic bags and incubated in the 
dark at $20^{\circ} \mathrm{C}$. Immediately after pesticide application and 3, 7, 14, 21, 35, $56,70,100$ and 125 days after pesticide application triplicate samples from each treatment were removed from the incubator and stored at $-20{ }^{\circ} \mathrm{C}$ for pesticide analysis.

\subsection{Field experiment}

A field experiment was conducted in the same field site described above (Supplementary Data Fig. 1). The field site has been cultivated with winter cereals for the last five years. A randomized complete block design was established with four replicate plots $(4 \mathrm{~m} \times 15 \mathrm{~m})$ for each combination of pesticide $x$ dose rate. A 2-m wide buffer zone between plots was maintained to minimize possible cross-contamination between treatments. On the 7th November 2013, the field was seeded with a mixture of cereals (60\% Hordeum vulgare L., $25 \%$ Triticum spp., and 15\% Triticosecale sp.) and a weather station was installed in the field site to collect daily weather data (precipitation $(\mathrm{mm})$, mean daily air and soil temperature $\left({ }^{\circ} \mathrm{C}\right)$, solar radiation $\left(\mathrm{W} \mathrm{m}^{-2}\right)$, relative humidity and wind speed $\left(\mathrm{m} \mathrm{sec}^{-1}\right)$ ). On the 12 th November 2013, the pesticides IPU, TCZ and CHL were applied to the established plots at three rates, $\times 1, \times 2$ and $\times 5$ the recommended dose. The highest dose rate was selected in compliance with the maximum pesticide application rate allowed to be used for experimental purposes in Italy. Pesticides were applied with a backpack sprayer at a spaying rate of $250 \mathrm{~L} \mathrm{ha}^{-1}$ (exact dose rates are given in Supplementary Table 2). Four plots were not treated with pesticides to serve as untreated controls. Immediately after treatment and 3, 7, 14, 21, 35, 56, 70, 100 and 125 days after treatment, soil samples were collected from each plot to assess pesticide dissipation. Nine random samples collected from the top $10 \mathrm{~cm}$ of each plot were homogenized providing a composite sample per plot. Each sampling point was marked with a wooden stick to avoid sampling from the same point in the following sampling campaigns. All samples were stored at $-20^{\circ} \mathrm{C}$ until further analysis.

\subsection{Soil adsorption of pesticides and their transformation products}

The adsorption of the tested substances was determined using the standard batch equilibrium method according to the OECD guideline106 (OECD, 2000). Preliminary kinetic studies were employed to determine the most appropriate soil: solution ratios and equilibration times for all chemicals. Thus, the most appropriate soil: solution ratios to achieve 20 to $80 \%$ adsorption of the studied chemicals were $1: 10$ for IPU, MD-IPU, and DD-IPU; 1:50 for 4-IA; 1:25 for TCZ; 1:200 for $\mathrm{CHL}$; and 1:5 for TCP. Equilibrium was reached within $24 \mathrm{~h}$ for all the tested substances except for CHL and TCP, for which equilibrium was reached at $12 \mathrm{~h}$. Stock solutions of each substance in acetone $\left(1 \mathrm{~g} \mathrm{~L}^{-1}\right)$ or methanol ( $4 \mathrm{~g} \mathrm{~L}^{-1}$ ) (only for CHL due to its low water solubility) were prepared using analytical standards. Appropriate amounts of the stock solutions were dissolved in $0.01 \mathrm{M} \mathrm{CaCl}_{2}$ leading to the preparation of six solutions with pesticide concentrations ranging from 5 to $50 \mathrm{mg} \mathrm{L}^{-1}$ for IPU, 2 to $20 \mathrm{mg} \mathrm{L}^{-1}$ for TCZ, and 3 to $40 \mathrm{mg} \mathrm{L}^{-1}$ for CHL. Regarding pesticides transformation products, a series of solutions with concentrations ranging from 1 to $10 \mathrm{mg} \mathrm{L}^{-1}$ were used. The range of concentrations used for each compound in the adsorption study was selected assuming i) application of the recommended dose rate for each compound (Supplementary Table 2), ii) soil bulk density of $1.3 \mathrm{~g} \mathrm{~mL}^{-1}$ and iii) soil moisture content of $20 \%$. Regarding transformation products, the concentrations used were based on their amounts formed in the laboratory and field dissipation studies. In all cases, the content of the organic solvent in the final solution phase did not exceed $0.1 \%$. Triplicate soil samples ( 1 to $10 \mathrm{~g}$ ) were mixed with 50 or $200 \mathrm{~mL}$ of each of the above solutions in screw-cupped vials and they were shaken overnight on an orbital shaker (200 rpm) at room temperature. When equilibrium was reached, samples were centrifuged at $2500 \mathrm{rpm}$ for $5 \mathrm{~min}$ and the supernatant was collected, extracted and analyzed by HPLC with a photodiode array (HPLC-PDA) detector as described below. The adsorption of the model pesticides was also determined using commercial formulations instead of analytical standards, following the same procedure with the only difference that pesticides were directly dissolved in $0.01 \mathrm{M} \mathrm{CaCl}_{2}$ without the need for organic solvent addition.

\subsection{Pesticide residue analysis}

\subsubsection{Extraction of pesticides and their transformation products from soil}

All studied compounds, except 4-IA, were extracted from soil with the same procedure. Thus, sealed glass bottles $(250 \mathrm{~mL})$ containing $40 \mathrm{~g}$ of soil, $2 \mathrm{~mL}$ of $2 \mathrm{M}$ ammonium acetate and $50 \mathrm{~mL}$ of acetone

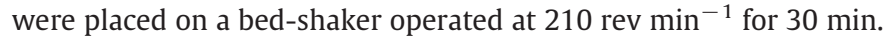
The extract was passed through a glass-fiber filter (Whatman GF/F) on a Buchner funnel under vacuum. The soil was re-extracted with $50 \mathrm{~mL}$ of acetone and the two extracts were pooled and mixed with $200 \mathrm{~mL}$ of a $4 \%$ solution of anhydrous sodium sulfate and $100 \mathrm{~mL}$ dichlorometh-

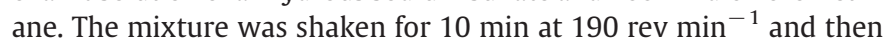
allowed the phases to separate: an aqueous upper phase and a dichloromethane lower phase. The organic phase was collected while the aqueous phase was re-extracted twice with $50 \mathrm{~mL}$ of dichloromethane. The organic phase from all extraction steps was pooled and passed through a glass column containing $1 \mathrm{~g}$ of glass wool and $40 \mathrm{~g}$ of anhydrous sodium sulfate. The filtrates were collected in a round bottom flask and evaporated to dryness on a rotary evaporator at $40^{\circ} \mathrm{C}$. Pesticide residues were re-dissolved in $10 \mathrm{~mL}$ dichloromethane and brought to complete dryness under a stream of nitrogen gas. The final pesticide residues were re-dissolved in $1 \mathrm{~mL}$ of methanol: $\mathrm{H}_{2} \mathrm{O}+0.01 \% \mathrm{H}_{3} \mathrm{PO}_{4}$ (70:30, v/ v) and analyzed by HPLC-PDA.

4-IA was extracted from soil samples according to the protocol proposed by Fenoll et al. (2012) with slight modifications. Briefly, $10 \mathrm{~g}$ of soil were extracted with $10 \mathrm{~mL}$ of acetonitrile:water $(1: 1, \mathrm{v} / \mathrm{v})$ by $30 \mathrm{~min}$ sonication followed by a salting-out step of $2 \mathrm{~g} \mathrm{NaCl}$. The tube was then vortexed for $1 \mathrm{~min}$ and centrifuged for $10 \mathrm{~min}$ at $4500 \mathrm{rpm}$. An aliquot of the supernatant was analyzed by HPLC-PDA.

\subsubsection{HPLC-PDA analyses}

Analyses were performed in a HPLC $1100 \mathrm{HP}$ system, equipped with a UV/VIS PDA detector. A Gemini C18 $(4 \times 2.0 \mathrm{~mm}$ ID) (SecurityGuard Cartridges) pre-column, connected to a Gemini $3 \mu \mathrm{m}-\mathrm{C} 18$ column $110 \mathrm{~A}(150 \mathrm{~mm} \times 2 \mathrm{~mm}$ i.d.) (Phenomenex, Cheshire, UK) was used for separation of the studied pesticides. The injection volume was $20 \mu \mathrm{L}$, the flow rate of the mobile phase was $0.3 \mathrm{~mL} \mathrm{~min}^{-1}$ and the column temperature was set at $25{ }^{\circ} \mathrm{C}$. Separation of compounds was achieved following a gradient elution program of a mobile phase composed of (A) acetonitrile and (B) $\mathrm{H}_{2} \mathrm{O}$ acidified with ortho-phosphoric acid ( $0.01 \%$ by volume). At the time of injection the solvent composition was $30 \% \mathrm{~A}$ and $70 \% \mathrm{~B}$. This was maintained for 5 min increased linearly to $80 \% \mathrm{~A}$ and $20 \% \mathrm{~B}$ until $15 \mathrm{~min}$ where it was maintained until $32 \mathrm{~min}$. The mobile phase was then reverted to its initial composition (30\% A and $70 \%$ B) until 35 min, followed by a further stabilization period of $3 \mathrm{~min}$. Detection was achieved at $240 \mathrm{~nm}$ for IPU, MD-IPU, and DDIPU, at $220 \mathrm{~nm}$ for TCZ, and at $230 \mathrm{~nm}$ for CHL and TCP. Pesticides were quantified by the external standard method using calibration curves obtained by the injection of matrix-matched standard solutions. Matrix-matched standard solutions were prepared by diluting the methanolic working solutions of each of the studied compounds in blank soil extract.

Analysis of 4-IA was achieved under isocratic elution conditions with a mobile phase composed of a 30:70 (v:v) mixture of (A) acetonitrile + methanol ( $1: 1$ by volume) acidified with acetic acid

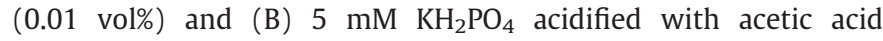
(0.01 vol\%) (Juhler et al., 2001). Total analysis time was $30 \mathrm{~min}$. The injection volume was $20 \mu \mathrm{L}$, the flow rate was $0.3 \mathrm{~mL} \mathrm{~min}^{-1}$ and the column temperature was set at $45^{\circ} \mathrm{C}$. Detection of 4-IA was achieved at $240 \mathrm{~nm}$. 


\subsubsection{Analytical method validation}

Analysis of soil samples fortified at three levels $(0.05,1$ and $10 \mathrm{mg} \mathrm{kg}^{-1}$ for pesticides, and $0.1,0.5,2.5 \mathrm{mg} \mathrm{kg}^{-1}$ for their transformation products) was employed to assess the efficiency of the extraction methods described above. Triplicate samples for each compound and concentration level were processed. The mean percentage recoveries for IPU, TCZ, and CHL were $86.7 \%, 86.4 \%$, and $88.1 \%$, respectively ( $C V \leq 15.3 \%$ ), while the recoveries for MD-IPU, DD-IPU, 4-IA, and TCP were $77.6 \%, 70.1 \%, 101.9$, and $82.2 \%$, respectively (CV $\leq 15.3 \%$ ). The limit of detection was $0.5 \mu \mathrm{gg}^{-1}$ for IPU, TCZ, and DD-IPU; $0.75 \mu \mathrm{g} \mathrm{kg}^{-1}$ for MD-IPU, CHL, and TCP; and $10 \mu \mathrm{gg}^{-1}$ for 4-IA. The limit of quantification was $1.25 \mu \mathrm{g} \mathrm{kg}^{-1}$ for IPU, TCZ, and DD-IPU; $2.5 \mu \mathrm{g} \mathrm{kg}^{-1}$ for MD-IPU, CHL, and TCP; and $25 \mu \mathrm{g} \mathrm{kg}^{-1}$ for 4 -IA.

\subsection{Calculation of dissipation kinetic parameters}

The four kinetic models proposed by the FOCUS working group on pesticide degradation kinetics (FOCUS, 2006) were used to calculate pesticide dissipation kinetic parameters: the single first order kinetic model (SFO), and the biphasic models hockey stick (HS), first order multi-compartment model (FOMC) and double first order in parallel model (DFOP). The goodness of fit was assessed using the $\chi^{2}$ test as well as visual inspection and the distribution of the residuals. In general, the biphasic kinetic models were used only in cases where the linear model (SFO) failed to acceptably describe $\left(\chi^{2}>15 \%\right)$ pesticides dissipation. Regarding the dissipation kinetics of the transformation products, the guidelines of the FOCUS working group on pesticides degradation kinetics were followed (FOCUS, 2006). Briefly the $\mathrm{DT}_{50 \mathrm{~s}}$ of the transformation products produced either directly from the parent compound (i.e. MD-IPU, TCP) or through the transformation of a preceding metabolite (DD-IPU), were calculated using the following assumptions: i) there was a flow of the parent compound to a sink (unidentified

(a)

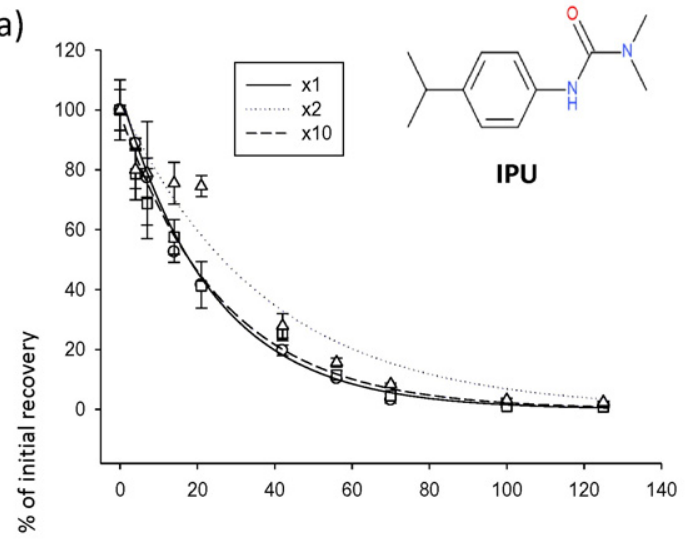

(c)

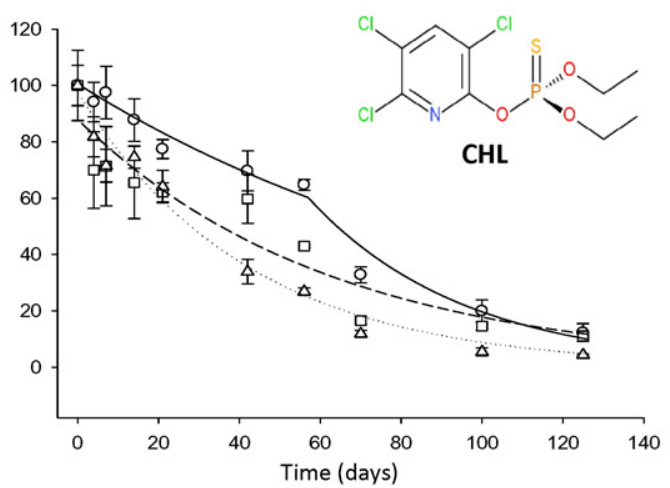

metabolites or bound residues), ii) the dissipation of the parent compound and the transformation products followed first-order kinetics and iii) the initial concentration for all compounds was the one measured at time 0 . The endpoints needed to be calculated were the initial amount (Pini), and the transformation rate constant of the parent compound $(\mathrm{kP})$, the formation fraction (ff), and transformation rate constant for each transformation product $(\mathrm{kM})$. Finally, the $\mathrm{DT}_{50}$ values for the transformation products were calculated by the following equation DT50 Transformation product $=\frac{\ln 2}{\mathrm{kM}}$. Parameters of the kinetic models and their standard errors were obtained by least square non-linear regression analysis using the statistical program $\mathrm{R}$ and the mkin package (version 09.40, 2015).

\section{Results}

\subsection{Laboratory study}

\subsubsection{Dissipation and transformation of IPU}

The dissipation patterns of IPU in all three dose rates were well described $\left(\chi^{2}<15 \%\right.$ ) by the SFO kinetic model (Fig. 1a, Supplementary Data Table 3 ) with estimated $\mathrm{DT}_{50}$ values increasing with the dose rate; $16.5,18.2$ and 25.7 days for the $\times 1, \times 2$ and $\times 10$ dose rates, respectively (Table 1). IPU dissipation proceeded via sequential demethylation to MD-IPU (Fig. 2a), which constituted the major transformation product of IPU, and to DD-IPU, which was formed in lower amounts (Fig. 2b). No residues of 4-IA were detected throughout the study. The formation of the two transformation products of IPU peaked between 14 and 21 days for all the different doses applied to the soil and dissipated thereafter. Their dissipation followed SFO kinetics with estimated $\mathrm{DT}_{50}$ values of 13.0, 14.5 and 15.0 days for MD-IPU, and 13.8, 12.0, and 22.5 days for DD-IPU in the samples treated with the $\times 1, \times 2$ and $\times 10$ dose rates, respectively (Table 1 ).

(b)

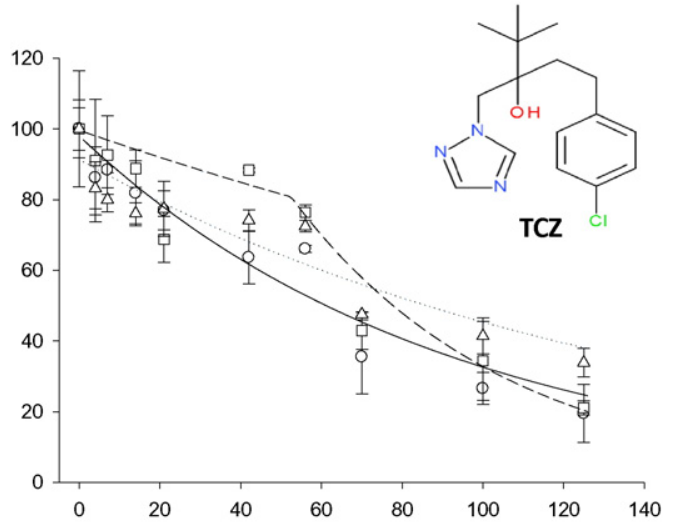

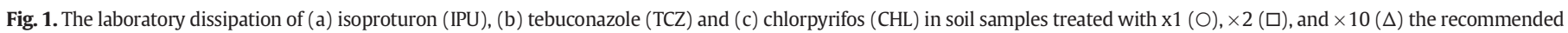
dose of each of these compounds. Each value is the mean of three replicates \pm the standard deviation. 
Table 1

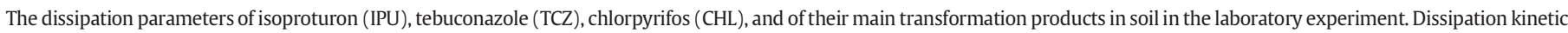
parameters were calculated with the single first order (SFO) kinetic model or the biphasic First Order Multi-compartment (FOMC) model.

\begin{tabular}{|c|c|c|c|c|c|c|c|c|c|}
\hline Substance & Kinetic model & $\mathrm{k}\left(\mathrm{d}^{-1}\right)$ & $\mathrm{a}$ & $\mathrm{b}$ & $\mathrm{k}_{\mathrm{M}}\left(\mathrm{d}^{-1}\right)$ & $\mathrm{ff}^{\mathrm{a}}$ & $\mathrm{DT}_{50}(\mathrm{~d})$ & $\mathrm{DT}_{90}(\mathrm{~d})$ & $\chi^{2}(\%)$ \\
\hline $\mathrm{IPU} \times 1$ & SFO & 0.042 & & & & & 16.5 & 25.0 & 4.3 \\
\hline IPU $\times 2$ & & 0.038 & & & & & 18.2 & 60.6 & 6.8 \\
\hline $\mathrm{IPU} \times 10$ & & 0.027 & & & & & 25.7 & 85.3 & 14.7 \\
\hline MD-IPU $\times 1$ & SFO & & & & 0.042 & 0.331 & 13.0 & 43.2 & 17.2 \\
\hline MD-IPU $\times 2$ & & & & & 0.048 & 0.293 & 14.5 & 48.2 & 14.4 \\
\hline MD-IPU $\times 10$ & & & & & 0.044 & 0.229 & 14.9 & 49.8 & 13.3 \\
\hline DD-IPU $\times 1$ & SFO & & & & 0.050 & 1.0 & 13.8 & 45.9 & 28.0 \\
\hline DD-IPU $\times 2$ & & & & & 0.057 & 1.0 & 12.0 & 39.8 & 28.6 \\
\hline DD-IPU × 10 & & & & & 0.030 & 1.0 & 22.5 & 74.8 & 22.9 \\
\hline $\mathrm{TCZ} \times 1$ & FOMC & & $1.26 \times 10^{7}$ & $1.11 \times 10^{9}$ & & & 60.7 & 201.6 & 8.1 \\
\hline $\mathrm{TCZ} \times 2$ & & & $3.34 \times 10^{5}$ & $3.60 \times 10^{7}$ & & & 74.8 & 248.6 & 12.8 \\
\hline $\mathrm{TCZ} \times 10$ & & & $1.41 \times 10^{6}$ & $1.94 \times 10^{8}$ & & & 97.1 & 315.8 & 8.2 \\
\hline $\mathrm{CHL} \times 1$ & FOMC & & $2.03 \times 10^{5}$ & $1.54 \times 10^{8}$ & & & 52.6 & 174.7 & 9.7 \\
\hline $\mathrm{CHL} \times 2$ & & & $1.17 \times 10^{6}$ & $7.44 \times 10^{5}$ & & & 43.9 & 146.0 & 14.7 \\
\hline $\mathrm{CHL} \times 10$ & & & $4.70 \times 10^{4}$ & $1.95 \times 10^{6}$ & & & 28.6 & 95.6 & 9.1 \\
\hline $\mathrm{TCP} \times 1$ & SFO & & & & 0.236 & 1.0 & 2.9 & 9.8 & 24.8 \\
\hline $\mathrm{TCP} \times 2$ & & & & & 0.317 & 0.999 & 2.2 & 7.3 & 23.7 \\
\hline $\mathrm{TCP} \times 10$ & & & & & 0.039 & 0.170 & 17.7 & 58.9 & 35.7 \\
\hline
\end{tabular}

a Formation factor of transformation products.

\subsubsection{Dissipation of TCZ}

TCZ dissipation showed a biphasic pattern (Fig. 1b) and it was best described by the FOMC model (Supplementary Data Table 3). The calculated $\mathrm{DT}_{50}$ values of TCZ showed an increasing trend with increasing dose rates; 60.7, 74.8 and 97.1 days in the soils treated with $\times 1, \times 2$ and $\times 10$ dose rates, respectively (Table 1 ).

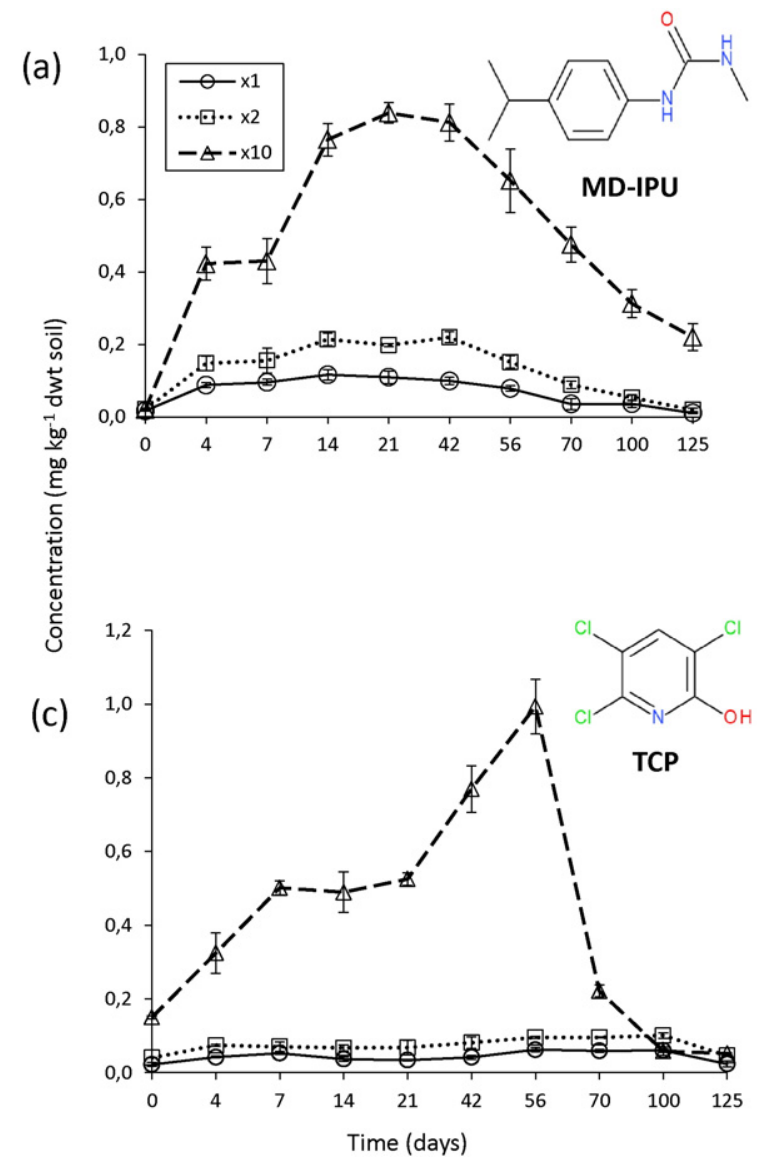

3.1.3. Dissipation and transformation of $\mathrm{CHL}$

The dissipation of CHL showed a biphasic pattern (Fig. 1c). The FOMC model provided the best fit to the dissipation data (Supplementary Data Table 3) with $\mathrm{DT}_{50}$ values showing a decreasing trend with increasing dose rates; 52.6, 43.9 and 28.6 days in the $\times 1, \times 2$ and $\times 10$ dose rates (Table 1 ), respectively. CHL was transformed via hydrolysis (b)

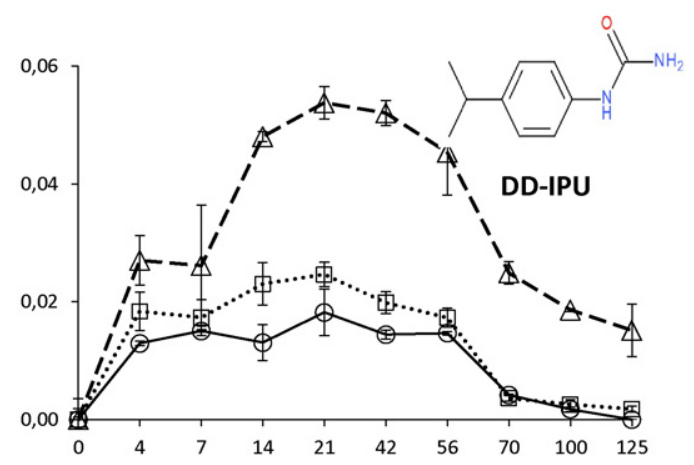

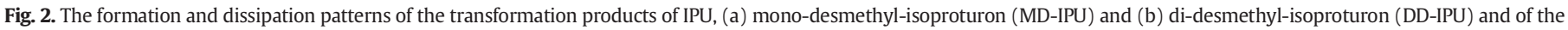

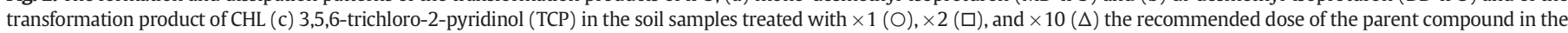
laboratory. Each value is the mean of three replicates \pm the standard deviation. 
to TCP whose formation reached a maximum between 56 and 100 days after application and dissipated thereafter (Fig. 2c). Its dissipation was best described by the SFO model with $\mathrm{DT}_{50}$ values of $2.9,2.2$, and 17.7 days for the $\times 1, \times 2$ and $\times 10$ dose rates, respectively (Table 1 ).

\subsection{Field study}

Weather data were collected during the field study (Supplementary Data Fig. 2). Eight intense precipitation events with daily mean precipitation $>10 \mathrm{~mm}$ and seven with mean daily precipitation $>5 \mathrm{~mm}$ occurred during the field study. The most important precipitation events occurred in the following periods: $3-11,43-53$, and 73-107 days after treatment. Temperature levels in soil and air ranged from -1 to $11^{\circ} \mathrm{C}$. The lowest temperatures were observed from 15 to 36 days (mean daily temperatures $<4{ }^{\circ} \mathrm{C}$ ); whereas an increase in temperatures was observed from 94 days onwards (mean daily temperature $>6{ }^{\circ} \mathrm{C}$ ). Solar radiation showed large fluctuations with no consistent pattern. Relative humidity and wind speed ranged from 60 to $100 \%$ and 0.1 to over $2.5 \mathrm{~m} \mathrm{sec}^{-1}$, respectively.

\subsubsection{Dissipation and transformation of IPU}

In contrast to the laboratory microcosm experiment, IPU dissipation in the field showed a biphasic pattern characterized by an initial rapid dissipation phase lasting for two weeks and followed by a slow dissipation phase until the end of the experiment (Fig. 3a). The HS model showed the best fit to the dissipation data (Supplementary Data Table 4) with calculated $\mathrm{DT}_{50 \text { s }}$ of $7.4,10.4$ and 12.8 days for the $\times 1, \times 2$, and $\times 5$ dose rates, respectively (Table 2 ). Similarly to the laboratory experiment, MD-IPU was the major transformation product while low amounts of DD-IPU were also detected (Fig. 4a and 4b). MD-IPU concentrations peaked between 14 and 35 days compared to DD-IPU whose concentrations in soil peaked at 35 days. The transformation products of IPU did not persist and dissipated with SFO-obtained DT 50s $_{\text {s }}$ of 9.1, 27.1 and 39.4 days for MD-IPU, and 6.9, 14.1, and 18.9 days for DD-IPU in the plots treated with the $\times 1, \times 2$ and $\times 5$ dose rates, respectively.

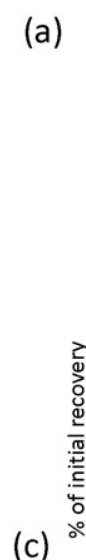

(a)

(c)

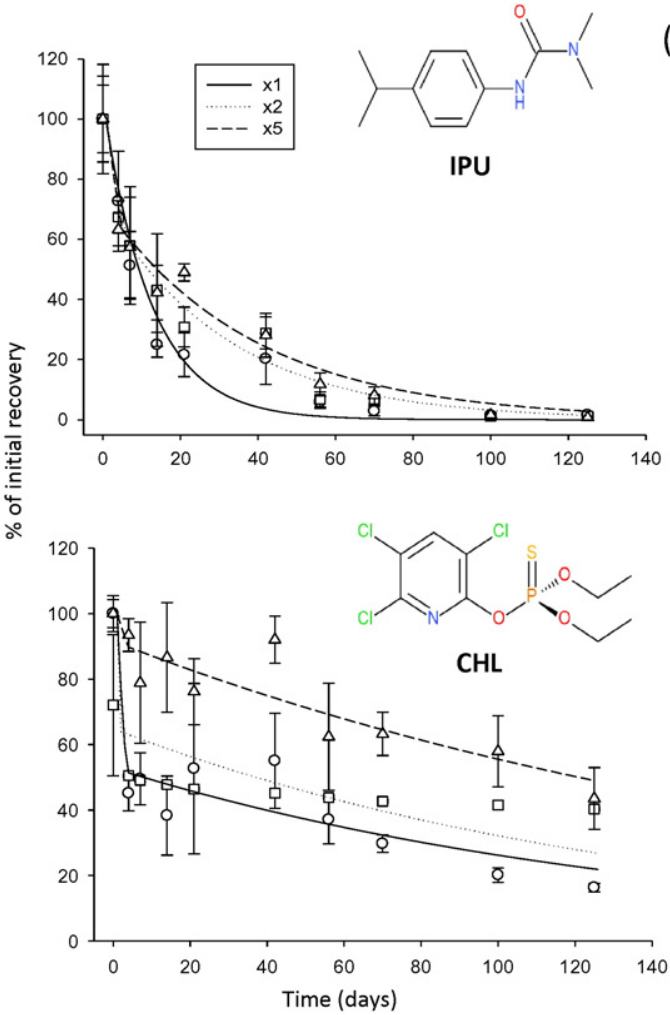

Table 2

The dissipation kinetics of isoproturon (IPU), tebuconazole (TCZ), chlorpyrifos (CHL) and of their main transformation products in soil in the field experiment. Dissipation parameters were obtained by fitting either the single first order (SFO) kinetic model or the biphasic model Hockey Stick (HS).

\begin{tabular}{|c|c|c|c|c|c|c|c|c|}
\hline Treatment & $\begin{array}{l}\text { Kinetic } \\
\text { Model }\end{array}$ & $\begin{array}{l}\mathrm{k}_{1} \\
\left(\mathrm{~d}^{-1}\right)\end{array}$ & $\begin{array}{l}\mathrm{k}_{2} \\
\left(\mathrm{~d}^{-1}\right)\end{array}$ & $\begin{array}{l}\mathrm{k}_{\mathrm{M}} \\
\left(\mathrm{d}^{-1}\right)\end{array}$ & $\mathrm{ff}^{\mathrm{a}}$ & $\begin{array}{l}\mathrm{DT}_{50} \\
\text { (d) }\end{array}$ & $\begin{array}{l}\mathrm{DT}_{90} \\
\text { (d) }\end{array}$ & $\begin{array}{l}\chi^{2} \\
(\%)\end{array}$ \\
\hline IPU $\times 1$ & HS & 0.014 & 0.026 & & & 7.4 & 51.5 & 9.1 \\
\hline $\mathrm{IPU} \times 2$ & & 0.098 & 0.031 & & & 10.4 & 61.1 & 10.7 \\
\hline $\mathrm{IPU} \times 5$ & & 0.115 & 0.026 & & & 12.8 & 73.1 & 10.5 \\
\hline $\begin{array}{l}\text { MD-IPU } \\
\times 1\end{array}$ & SFO & & & 0.076 & 0.455 & 9.1 & 30.4 & 31.5 \\
\hline $\begin{array}{l}\text { MD-IPU } \\
\times 2\end{array}$ & & & & 0.046 & 0.180 & 27.1 & 90.0 & 27.1 \\
\hline $\begin{array}{l}\text { MD-IPU } \\
\times 5\end{array}$ & & & & 0.018 & 0.079 & 39.4 & 130.8 & 22.3 \\
\hline $\begin{array}{c}\text { DD-IPU } \\
\times 1\end{array}$ & SFO & & & 0.100 & 0.501 & 6.9 & 22.9 & 36.8 \\
\hline $\begin{array}{c}\text { DD-IPU } \\
\times 2\end{array}$ & & & & 0.049 & 0.801 & 14.1 & 48.8 & 33.3 \\
\hline $\begin{array}{c}\text { DD-IPU } \\
\times 5\end{array}$ & & & & 0.036 & 0.900 & 18.9 & 62.7 & 34.6 \\
\hline $\mathrm{TCZ} \times 1$ & HS & 1.493 & 0.006 & & & 1.5 & 198.0 & 9.1 \\
\hline $\mathrm{TCZ} \times 2$ & & 0.297 & 0.002 & & & 2.3 & 603.4 & 19.6 \\
\hline $\mathrm{TCZ} \times 5$ & & 0.273 & 0.008 & & & 2.5 & 186.6 & 14.6 \\
\hline $\mathrm{CHL} \times 1$ & HS & 0.259 & 0.007 & & & 6.7 & 228.5 & 14.2 \\
\hline $\mathrm{CHL} \times 2$ & & 0.765 & 0.007 & & & 33.9 & 249.2 & 17.4 \\
\hline $\mathrm{CHL} \times 5$ & & 0.037 & 0.005 & & & 119.6 & 440.6 & 8.7 \\
\hline $\mathrm{TCP} \times 1$ & SFO & & & 0.013 & 0.166 & 52.8 & 175.4 & 18.3 \\
\hline $\mathrm{TCP} \times 2$ & & & & 0.014 & 0.135 & 49.1 & 163.1 & 18.8 \\
\hline $\mathrm{TCP} \times 5$ & & & & 0.040 & 0.371 & 17.4 & 57.8 & 27.5 \\
\hline
\end{tabular}

a formation factor of transformation products.

\subsubsection{Dissipation of tebuconazole}

The field dissipation of TCZ showed a clear biphasic pattern with a drastic decline in its concentrations during the first 3 days, when the first precipitation event of $6.4 \mathrm{~mm}$ occurred, followed by a slow (b)

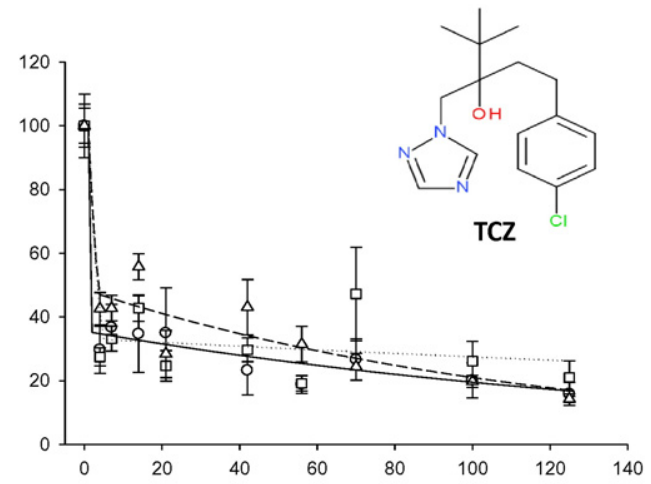

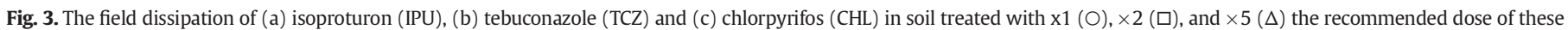
compounds. Each value is the mean of three replicates \pm the standard deviation. 

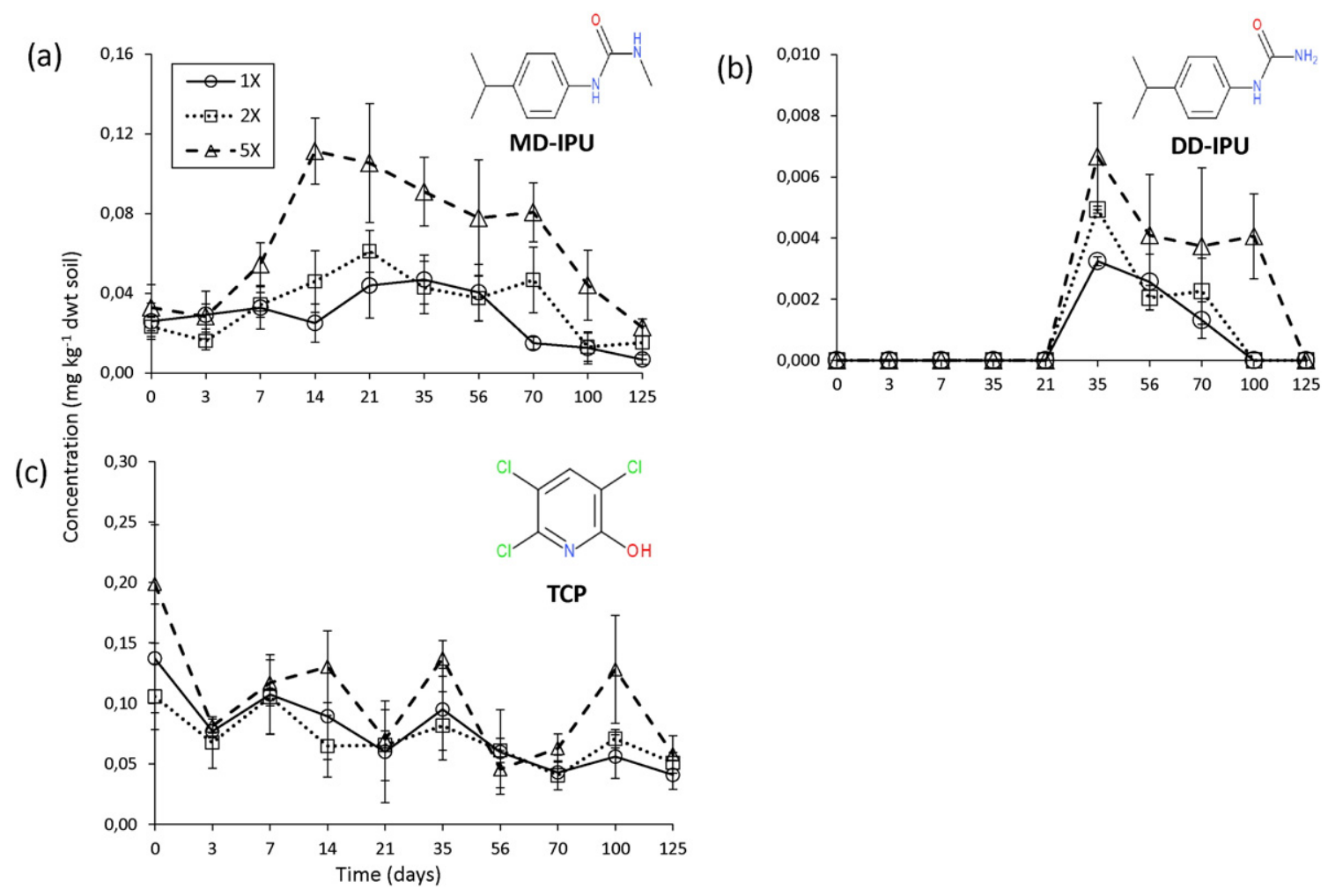

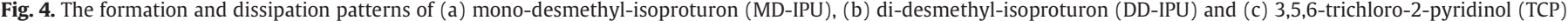

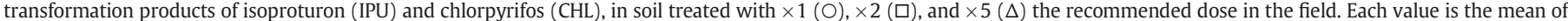
three replicates \pm the standard deviation.

dissipation phase until the end of the experiment (Fig. 3b). This dissipation pattern of TCZ was best described by the HS model (Supplementary Data Table 4) with $\mathrm{DT}_{50}$ values of $1.5,2.3$ and 2.5 days for the $\times 1, \times 2$ and $\times 5$ dose rates, respectively (Table 2 ). Extrapolated $\mathrm{DT}_{90}$ values of 198 , $603.4,186.7$ days for the $\times 1, \times 2$ and $\times 5$ dose rates, respectively, showed a much longer persistence of TCZ (Table 2 ).

\subsubsection{Dissipation and transformation of chlorpyrifos}

As observed for the two other pesticides, the dissipation of CHL in the field experiment was biphasic and it was best described by the HS model (Supplementary Data Table 4) with $\mathrm{DT}_{50 \text { s }}$ of $6.7,33.9$ and 119.6 days in the plots treated with the $\times 1, \times 2$ and $\times 5$ dose rates, respectively (Fig. 3c, Table 2). In accordance with the results of the laboratory microcosm experiment, TCP was the only detected transformation product of CHL (Fig. 4c). The dissipation of TCP for all dose rates was best described by the SFO model with estimated $\mathrm{DT}_{50}$ values of 52.8 , 49.1, and 17.4 days for the $\times 1, \times 2$ and $\times 5$ dose rates, respectively (Table 2).

\subsection{Soil adsorption of pesticides and their transformation products}

The adsorption of pesticides and their transformation products were fitted to the Freundlich equation $\left(R^{2}>0.96\right)$ which was used for the calculation of the adsorption coefficients $K_{f}$ and $K_{f o c}$ (Fig. 5, Table 3). IPU, MD-IPU and DD-IPU showed a weak adsorption affinity in the tested

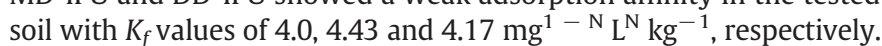
On the contrary, 4-IA showed a higher adsorption affinity with a $K_{f}$ value of $34.9 \mathrm{mg}^{1-\mathrm{N}} \mathrm{L}^{\mathrm{N}} \mathrm{kg}^{-1}$. IPU adsorption affinity increased when

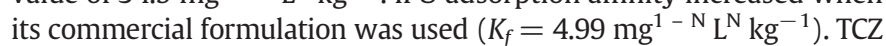
was moderately adsorbed to soil components with $K_{f}$ values of 21.9 and $30.1 \mathrm{mg}^{1-\mathrm{N}} \mathrm{L}^{\mathrm{N}} \mathrm{kg}^{-1}$, for the active substance and the commercial formulation, respectively. CHL showed the highest adsorption affinity with $K_{f}$ values of 195.2 and $211.4 \mathrm{mg}^{1-\mathrm{N}} \mathrm{L}^{\mathrm{N}} \mathrm{kg}^{-1}$, for the active substance and the commercial formulation, respectively. In contrast, the hydrolysis product of $\mathrm{CHL}, \mathrm{TCP}$, showed the weakest adsorption affinity among all the tested substances $\left(K_{f}=1.55 \mathrm{mg}^{1-\mathrm{N}} \mathrm{L}^{\mathrm{N}} \mathrm{kg}^{-1}\right)$. According to the classification system of isotherms introduced by Giles et al. (1960), MD-IPU, DD-IPU, and TCP gave a C-type isotherm compared to the rest of the compounds studied which gave L-shaped isotherms.

\section{Discussion}

Estimation of the dissipation of pesticides in soil constitutes an integral part of pesticide environmental risk assessment required for the authorization and placement on the market of plant protection products. We investigated the dissipation and the transformation of three model pesticides following a lab-to-field experimental approach as a proxy of the scenario of soil exposure to pesticides and their main transformation products.

\subsection{Dissipation and transformation of isoproturon}

IPU showed the lowest persistence from the pesticides tested with $\mathrm{DT}_{50 \text { s }}$ which were within the range reported in the literature (6.5 to 40 days) (Walker et al., 2001; Rodríguez-Cruz et al., 2006). A trend towards reduced $\mathrm{DT}_{50}$ values of IPU in the field compared to the corresponding $\mathrm{DT}_{50}$ values in the laboratory was observed. This is in line with previous studies for other pesticides (Laabs et al., 2000; Dolaptsoglou et al., 2009) and it is not surprising considering that in laboratory studies the contribution of other dissipation processes like volatilization, leaching or photolysis are impeded (volatilization) or eliminated (leaching and photolysis) compared to field studies where these processes may significantly contribute to pesticide loss (EEC, 2000). 
(a)

(c)
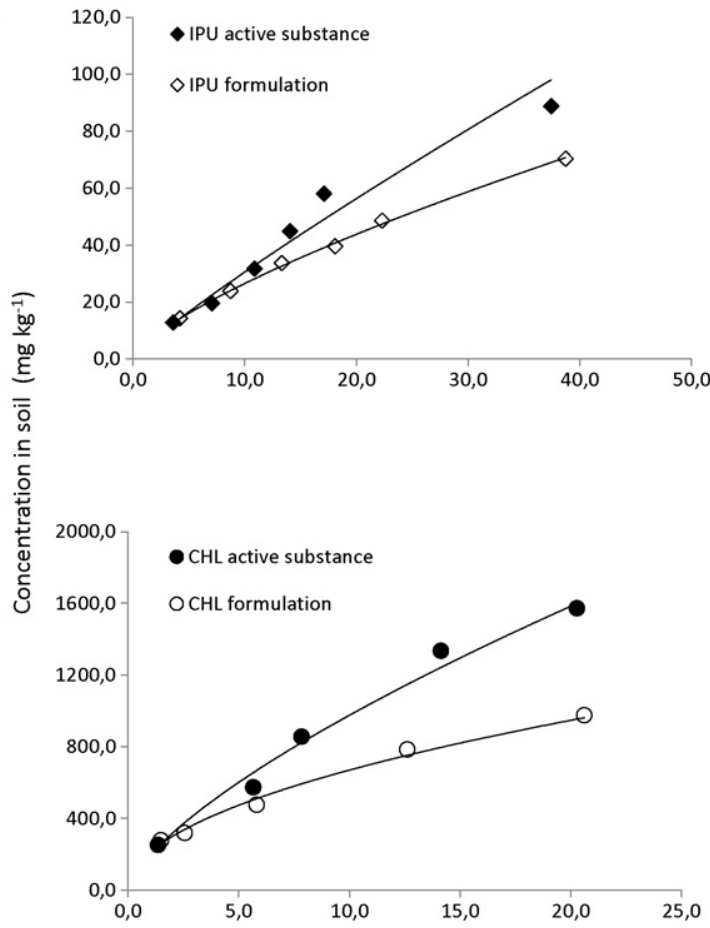

(b)

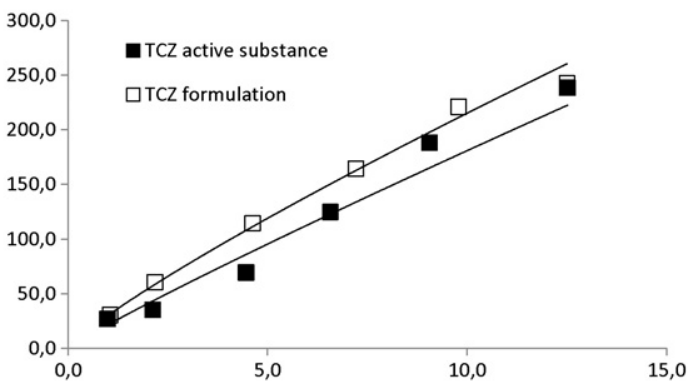

(d)

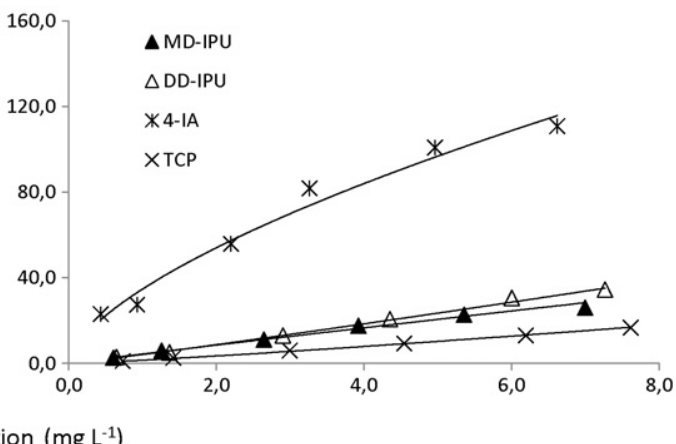

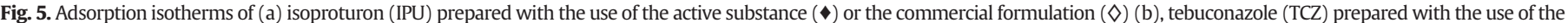

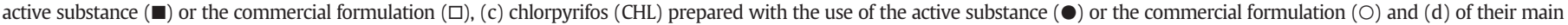

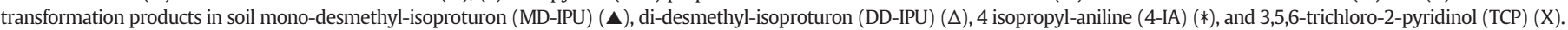

IPU dissipation in soil proceeded via sequential demethylation to MD-IPU which was the main transformation product, and to DD-IPU which was a minor transformation product. This is in agreement with previous studies which showed that early stages of IPU transformation by soil microorganisms proceeds via successive demethylations (Sørensen et al., 2001), followed by cleavage of the urea side chain resulting in the transitory accumulation of 4-IA (Hussain et al., 2009) which was not detected in our study. 4-IA has been previously detected in liquid cultures of microorganisms degrading IPU (Johannesen et al., 2003; Sørensen and Aamand, 2001) but it has been rarely detected in soil studies (Mudd et al., 1983). Our adsorption studies confirmed that 4-IA was strongly adsorbed onto soil colloids. Thus, it is probable that the transformation of IPU in our study led to the formation of 4-IA which became strongly bound to soil colloids and it was not available for extraction.

The demethylated transformation products of IPU were transitory and did not accumulate in soil. Their dissipation rates in both laboratory

Table 3

The adsorption coefficients of isoproturon (IPU), tebuconazole (TCZ), chlorpyrifos (CHL) determined either with the use of the active substance or the commercial formulation. The adsorption coefficients of the transformation products of the studied pesticides are also given including mono-desmethyl-isoproturon (MD-IPU), di-desmethyl-isoproturon (DD-IPU), 4 isopropyl-aniline (4-IA), and 3,5,6-trichloro-2-pyridinol (TCP).

\begin{tabular}{llclc}
\hline Substances & $\mathrm{R}^{2}$ & $K_{f}\left(\mathrm{mg}^{1-\mathrm{N}} \mathrm{L}^{\mathrm{N}} \mathrm{kg}^{-1}\right)$ & $N$ & $K_{f o c}\left(\mathrm{mg}^{1-\mathrm{N}} \mathrm{L}^{\mathrm{N}} \mathrm{kg}^{-1}\right)$ \\
\hline IPU active substance & 0.974 & 4.00 & 0.885 & 263.3 \\
IPU formulation & 0.998 & 4.99 & 0.725 & 328.3 \\
MD-IPU & 0.994 & 4.43 & 0.955 & 291.6 \\
DD-IPU & 0.994 & 4.17 & 1.076 & 274.5 \\
4-IA & 0.971 & 34.9 & 0.636 & 2299.2 \\
TCZ active substance & 0.960 & 21.9 & 0.923 & 1439.9 \\
TCZ formulation & 0.997 & 30.1 & 0.855 & 1980.4 \\
CHL active substance & 0.988 & 195.2 & 0.700 & $12,842.6$ \\
CHL formulation & 0.987 & 211.4 & 0.501 & $13,906.9$ \\
TCP & 0.998 & 1.55 & 1.176 & 102.25 \\
& & & \multicolumn{3}{c}{}
\end{tabular}

and field studies showed a decreasing trend with increasing dose rates in agreement with the dissipation behavior of the parent compound. No previous studies have investigated the dissipation kinetics of MDIPU and DD-IPU and their $\mathrm{DT}_{50 \text { s }}$ at both laboratory and field scale. The only data available are from the registration documents of IPU which reported laboratory DT $_{50}$ values of $10.5-100.5$ for MD-IPU and 38.478.1 days for DD-IPU (EFSA, 2015), which is in agreement with our findings.

\subsection{Dissipation of tebuconazole}

TCZ showed a moderate to high persistence in the laboratory study. Its $\mathrm{DT}_{50}$ values (60.7-97.1 days) were within the range reported by previous laboratory studies (Strickland et al., 2004; Potter et al., 2005; Li et al., 2015). However, they were significantly lower than the $\mathrm{DT}_{50 \mathrm{~s}}$ reported in the registration documents where ${ }^{14} \mathrm{C}$-labelled TCZ was used $\left(\mathrm{DT}_{50}>1\right.$ year) (EFSA, 2014). $\mathrm{DT}_{50}$ values measured under laboratory conditions indicated a trend for increasing persistence with increasing dose rate, in accordance with previous laboratory studies (Muñoz-Leoz et al., 2011; Wang et al., 2016).

TCZ showed a limited persistence in the field with $\mathrm{DT}_{50}$ values of 1.5-2.5 days for the different dose rates. Previous field studies have also showed a lower persistence of TCZ in the field compared to the laboratory (Herrero-Hernández et al., 2011; Wang et al., 2015). Despite that, the $\mathrm{DT}_{50 \mathrm{~s}}$ obtained for $\mathrm{TCZ}$ in the field study are at the lower part of the range of $\mathrm{DT}_{50}$ values reported in the literature which vary from 5.8-6.5 days (temperature $15-30{ }^{\circ} \mathrm{C}$ ) (Wang et al., 2015) to 91.6 days (average temperature $10.5{ }^{\circ} \mathrm{C}$ ) (EFSA, 2014). The reduced field persistence of TCZ observed in our study was the result of a biphasic dissipation pattern which was composed of a very rapid dissipation phase within the first 3 days (70\% dissipation) followed by a slow dissipation phase thereafter where limited loss of TCZ occurred. A more realistic measure of the soil exposure to TCZ would be given by the $\mathrm{DT}_{90}$ values which ranged from 198 to 603.4 days in agreement with the $\mathrm{DT}_{90}$ values 
reported for the field dissipation of TCZ (115-304 days) (EFSA, 2014). The rapid decline of TCZ observed in the field study during the first 3 days after application could not be attributed to a rapid degradation of TCZ as it is indicated by the moderate to high persistence of the compound in the laboratory where degradation, biotic or abiotic, constitutes the main dissipation process. Rapid formation of bound residues or movement of the pesticide below the top $10 \mathrm{~cm}$ of the soil have been proposed by Herrero-Hernández et al. (2011) as possible reasons to explain the initial rapid field dissipation of TCZ. The rapid formation of bound residues of TCZ is not fully supported by the moderate soil adsorption affinity of TCZ and previous regulatory studies which reported the formation of only $19.5 \%$ of soil bound residues after 30 days (EFSA, 2014). Significant losses of TCZ due to photolysis or volatilization are not expected considering its soil photostability and low volatility (EFSA, 2014). A precipitation event occurred at day 3 (Supplementary Data Fig. 2), right before the collection of the soil samples, might have facilitated the vertical leaching of a large fraction of TCZ residues below the top $10 \mathrm{~cm}$ which was the soil layer sampled. Regarding the second slow dissipation phase of TCZ, it could be attributed to a strongly adsorbed fraction of the pesticide that could be less accessible to dissipation processes (Muñoz-Leoz et al., 2011; Herrero-Hernández et al., 2011).

Previous studies have identified four main transformation products of TCZ: a lactone, a pentanoic acid, a triazolyl pinacoline, and a 5-keto derivative (Strickland et al., 2004; Potter et al., 2005). In contrast, regulatory documents suggest that 1,2,4-triazole is the most relevant metabolite of TCZ in soil, whereas the derivatives reported by Strickland et al. (2004) were only detected at trace amounts (EFSA, 2014). In the present study, no transformation products of TCZ were determined due to the lack of relevant analytical standards. However, a follow-up study combining suspect screening time-of-flight mass spectrometry with in silico molecular typology reported the presence of 22 empirical and 12 yet unknown transformation products of TCZ in the field experiment soil samples treated with $\times 5$ dose rate (Storck et al., 2016). Among them, some of the transformation products reported by Strickland et al. (2004) were found.

\subsection{Dissipation and transformation of chlorpyrifos}

CHL showed a moderate persistence with $\mathrm{DT}_{50 \text { s }}$ within the range reported in the literature: 10 to 120 days in laboratory studies (Racke, 1993; Papadopoulou et al., 2016) and 0.6 to 121 days in field studies (Jin and Webster, 1997; Laabs et al., 2002). In the laboratory study, the persistence of CHL decreased with increasing dose rates ( $\mathrm{DT}_{50 s} 28.6$ to 52.6 days in the $\times 10$ and $\times 1$ dose rate, respectively) which is not in accordance with the general trend for increasing CHL persistence at increasing application rates (John and Shaike, 2015) and to the opposite trend observed in the field experiment ( $\mathrm{DT}_{50 \mathrm{~s}} 6.7$ to 119.6 days in the $\times 1$ and $\times 5$ dose rate, respectively). The higher laboratory dissipation of CHL at increasing dose rates might be attributed to its high adsorption affinity (verified in our study) which at low dose rates in a static soil laboratory incubation system could be mostly adsorbed resulting in low bioavailability and longer persistence compared to the higher dose rates which might have saturated the soil adsorption sites and the remaining fraction of CHL is found dissolved in the soil solution phase where it was degraded by biotic and abiotic mechanisms. If we compare the persistence of $\mathrm{CHL}$ in the laboratory and in the field study at the two common dose rates $\times 1$ and $\times 2$, a faster field dissipation of CHL was evident, which is in agreement with the generally more rapid field dissipation of the other pesticides tested.

In both laboratory and field experiments, the dissipation of $\mathrm{CHL}$ proceeded via hydrolysis to TCP. Several previous studies have reported the vulnerability of CHL to hydrolysis in alkaline soils which is controlled by both abiotic and biotic processes (Racke et al., 1996; Singh et al., 2003). The accumulation of TCP upon hydrolysis of CHL in agricultural soils has been linked to the resistance of the parent compound to the phenomenon of enhanced biodegradation due to the antimicrobial characteristics of TCP (Racke et al., 1990). However, no accumulation of TCP was observed in our study and the TCP amounts formed were dissipated showing a contrasting dose-dependent pattern compared to the parent compound. In particular, the persistence of TCP in soil increased with increasing dose rates in the laboratory experiment, whereas the opposite trend was observed in the field experiment. Little is known regarding the dissipation rates of TCP and its fate upon CHL dissipation has been scarcely explored. In agreement with our findings, Baskaran et al. (2003) reported laboratory $\mathrm{DT}_{50}$ values of 42-49 days in topsoil and observed a contrasting dissipation behavior of TCP compared to its parent compound.

\subsection{Adsorption of pesticides and of their transformation products in soil}

Based on the dissipation patterns of the pesticides and their transformation products in the laboratory and the field study, we determined the soil adsorption of the studied compounds and of their main transformation products for which little is known. The three pesticides showed different soil adsorption affinity which increased in the following order IPU $<$ TCZ $<$ CHL. This is in accordance with the more hydrophobic character of CHL $\left(\log K_{o w} 4.7\right)$ followed by TCZ $\left(\log K_{o w} 3.7\right)$ and the more water soluble IPU $\left(\log K_{\mathrm{ow}} 2.5\right)$. The $K_{f}$ values obtained were within the range reported in the literature for IPU $\left(0.67-5.00 \mathrm{mg}^{1-\mathrm{N}} \mathrm{L}^{\mathrm{N}} \mathrm{kg}^{-1}\right)$ 1) (Benoit et al., 1998; EFSA, 2015), TCZ (30-80 mg ${ }^{1}-\mathrm{N}^{\mathrm{N}} \mathrm{kg}^{-1}$ ) (Čadková et al., 2013a,b) and CHL (116-271 mg ${ }^{1}-\mathrm{N}^{\mathrm{N}} \mathrm{kg}^{-1}$ ) (Gebremariam et al., 2012).

Based on the shape of the adsorption isotherms of the compounds studied we could obtain information on the adsorption mechanism. Thus the C-type isotherms of MD-IPU, DD-IPU, and TCP suggest a constant partition of these compounds between solution and substrate (Giles et al., 1960). On the other hand the L-shaped isotherms observed for all the other compounds suggest a high dependence of adsorption on the initial solution concentration of these compounds with higher adsorption observed at lower solute concentration (Teng and Chien-To, 1998).

In most cases adsorption studies are performed with the active substances although pesticides are applied in the field as commercial formulations which might exhibit a different adsorption behavior. All pesticides studied showed a higher soil adsorption affinity in the form of commercial formulations compared to the pure active substance. This is not surprising considering the presence of organic additives in the commercial formulations including dispersing or wetting agents and other surfactants that have the ability to decrease surface tension and facilitate the adsorption of pesticides onto soil mineral surfaces (Čadková et al., 2012). Previous studies have clearly demonstrated a positive effect of the commercial formulation on the adsorption of TCZ (Čadková et al., 2013a,b) while no such studies are available regarding the other two pesticides.

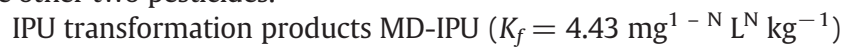
and DD-IPU $\left(K_{f}=4.17 \mathrm{mg}^{1-\mathrm{N}} \mathrm{L}^{\mathrm{N}} \mathrm{kg}^{-1}\right)$ showed an adsorption behavior similar to the parent compound $\left(K_{f}=4.00 \mathrm{mg}^{1-\mathrm{N}} \mathrm{L}^{\mathrm{N}} \mathrm{kg}^{-1}\right)$. On the contrary, 4-IA $\left(K_{f}=34.9 \mathrm{mg}^{1-\mathrm{N}} \mathrm{L}^{\mathrm{N}} \mathrm{kg}^{-1}\right)$ showed a substantially higher adsorption affinity than IPU, MD-IPU, and DD-IPU. Little is known about the adsorption behavior of IPU transformation products. Registration

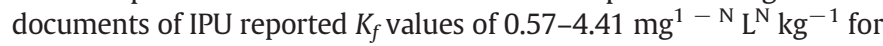
MD-IPU (EFSA, 2015), while studies by Johannesen et al. (2003) showed

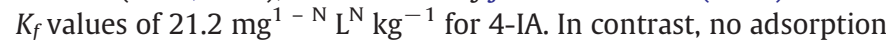
measurements are available for DD-IPU. Our adsorption data suggest that the demethylated transformation products of IPU are expected to be moderately mobile in soil similarly to the parent compound. In contrast to the high adsorption affinity of CHL, its hydrolysis product TCP exhibited low adsorption affinity $\left(K_{f}=1.55 \mathrm{mg}^{1-\mathrm{N}} \mathrm{L}^{\mathrm{N}} \mathrm{kg}^{-1}\right)$. This is in line with previous studies by Baskaran et al. (2003) who reported that TCP was 100 times less adsorbed than the parent compound. Our findings suggest that the accumulation of TCP in the soil environment 
could induce a reciprocal risk for the contamination of groundwater resources and should deserve greater attention in future environmental fate studies and pesticide risk assessment.

\section{Conclusions}

In the present study, we evaluated the soil dissipation and metabolism of three model pesticides, IPU, TCZ and CHL, following a tiered lab-to-field experimental approach. Overall, IPU was the least persistent chemical, showed an increasing persistence at increasing dose rates and it was demethylated to MD-IPU and DD-IPU. The latter showed similar dissipation as the parent compound. TCZ was the most persistent chemical in the laboratory compared to the field where it dissipated more rapidly following a biphasic pattern. Finally, CHL showed a contrasting dose-dependent behavior in the laboratory and in the field study and it was hydrolyzed to TCP which was further dissipated. Soil adsorption affinity increased in the order IPU $<\mathrm{TCZ}<\mathrm{CHL}$. The transformation products of IPU showed similar adsorption affinity to the parent compound, while TCP exhibited lower adsorption affinity compared to CHL. Our results provide a comprehensive determination of the duration and the level of exposure of the soil to the studied pesticides and their main transformation products and they will be utilized for assessing their soil microbial toxicity in follow up studies.

\section{Acknowledgements}

This study was conducted within the frame of the FP7-PEOPLE2012-IAPP (Industry-Academia Partnerships and Pathways) MarieCurie project 'Love-to-Hate: Pesticides: Felicity or curse for the soil microbial community?' which was funded by the European Commission (Grant Agreement No. 324349). The Ph.D. studies of Veronika Storck performed at the Doctoral School of Environment and Health (ED E2S) at the University of Burgundy (Grant number 2013-31) was funded by the French Ministry of Education and Research (MESR).

\section{Appendix A. Supplementary data}

Supplementary data to this article can be found online at http://dx. doi.org/10.1016/j.scitotenv.2016.06.133.

\section{References}

Alletto, L., Coquet, Y., Benoit, P., Bergheaud, V., 2006. Effects of temperature and water content on degradation of isoproturon in three soil profiles. Chemosphere 64 , $1053-1061$.

Álvarez-Martín, A., Sánchez-Martín, M.J., Pose-Juan, E., Rodríguez-Cruz, M.S., 2016. Effect of different rates of spent mushroom substrate on the dissipation and bioavailability of cymoxanil and tebuconazole in an agricultural soil. Sci. Total Environ. 550, 495-503.

Arias-Estévez, M., López-Periago, E., Martínez-Carballo, E., Simal-Gándara, J., Mejuto, J.-C. García-Río, L., 2008. The mobility and degradation of pesticides in soils and the pollution of groundwater resources. Agric. Ecosyst. Environ. 123, 247-260.

Baskaran, S., Kookana, R.S., Naidu, R., 2003. Contrasting behaviour of chlorpyrifos and its primary metabolite, TCP (3,5,6-trichloro-2-pyridinol), with depth in soil profiles. Aust. J. Soil Sci. 41, 749-760.

Benoit, P., Barriuso, E., Vidon, P., Real, B., 1998. Isoproturon sorption and degradation in a soil from grassed buffer strip. J. Environ. Qual. 28, 121-129.

Čadková, E., Komárek, M., Kaliszová, R., Száková, J., Vaněk, A., Bordas, F., Bollinger, J.-C., 2013b. The influence of copper on tebuconazole sorption onto soils, humic substances, and ferrihydrite. Environ. Sci. Pollut. Res. 20, 4205-4215.

Čadková, E., Komárek, M., Kaliszová, R., Vaněk, A., Balíková, M., 2013a. Tebuconazole sorption in contrasting soil types. Soil Sediment Contam. 22, 404-414

Čadková, E., Komárek, M., Kaliszová, R., Koudelková, V., Dvořák, J., Vaněk, A., 2012. Sorption of tebuconazole onto selected soil minerals and humic acids. J. Environ. Sci. Health Part B47, 336-342.

Collings, L.V., Blair, A.M., Gay, A.P., Dyer, C.J., Mackay, N., 2003. The effect of weather factors on the performance of herbicides to control Alopecurus myosuroides in winte wheat. Weed Res. 43, 146-153.

D'Angelo, D.L., Bradley, C.A., Ames, K.A., Willeyard, K.T., Madden, L.V., Paul, P.A., 2014. Efficacy of fungicide applications during and after anthesis against fusarium head blight and deoxynivalenol in soft red winter wheat. Plant Dis. 98, 1387-1397.
Dolaptsoglou, C., Karpouzas, D., Menkissoglu-Spiroudi, U., Eleftherohorinos, I., Voudrias, E.A., 2009. Influence of different organic amendments on the leaching and dissipation of terbuthylazine in a column and a field study. J. Environ. Qual. 38, 782-791.

EEC, 2000. Guidance Document No 9188/VI/97-ver. 8, Persistence in Soil, Commission of the European Communities, Directorate General for Agriculture, GG VI B II-1, Brussels, Belgium, Issued on July 2000.

European Food Safety Authority (EFSA), 2010. Scientific Opinion on the development of specific protection goal options for environmental risk assessment of pesticides, in particular in relation to the revision of the Guidance Documents on Aquatic and Terrestrial Ecotoxicology (SANCO/3268/2001 and SANCO/10329/2002). EFSA Panel on Plant Protection Products and their Residues. EFSA J. 8, 1821-1876.

European Food Safety Authority (EFSA), 2014. Conclusion on the peer review of the pesticide risk assessment of the active substance tebuconazole. EFSA J. 12, 3485.

European Food Safety Authority (EFSA), 2015. Conclusion on the peer review of the pesticide risk assessment of the active substance isoproturon. EFSA J. 13, 4206.

Fenoll, J., Hellín, P., Martínez, C.M., Flores, P., Navarro, S., 2012. High performance liquid chromatography-tandem mass spectrometry method for quantifying phenylurea herbicides and their main metabolites in amended and unamended soils. J. Chromatogr. A. 1257, 81-88.

FOCUS, 2006. Guidance document on estimating persistence and degradation kinetics from environmental fate studies on pesticides in EU registration. Report of the FOCUS Work Group on Degradation Kinetics, EC Document Reference Sanco/10058/ 2005 version 2.0, 2006 (434 pp.)

Gebremariam, S.Y., Beutel, M.W., Yonge, D.R., Flury, M., Harsh, J.B., 2012. Adsorption and desorption of chlorpyrifos to soils and sediments. Rev. Environ. Contam. Toxicol. $215,123-175$.

Giles, C.H., Macewans, T.H., Nakhwa, N., Smith, D., 1960. Studies in adsorption. Part XI. A system of classification of solution adsorption isotherms, and itsuse in diagnosis of adsorptionmechanisms and in measurement of specific surface areas of solids. J. Chem. Soc. 786, 3973-3993.

Herrero-Hernández, E., Andrades, M.S., Alvarez-Martina, A., Pose-Juana, E., RodriguezCruz, M.S., Sánchez-Martín, M.J., 2013. Occurrence of pesticides and some of their degradation products in waters in a Spanish wine region. J. Hydrol. 486, 234-245.

Herrero-Hernández, E., Andrades, M.S., Marín-Benito, J.M., Sánchez-Martín, M.J., Rodríguez-Cruz, M.S., 2011. Field-scale dissipation of tebuconazole in a vineyard soil amended with spent mushroom substrate and its potential environmental impact. Ecotoxicol. Environ. Saf. 74, 1480-1488.

Hussain, S., Arshad, M., Springael, D., SøRensen, S.R., Bending, G.D., Devers-Lamrani, M., Maqbool, Z., Martin-Laurent, F., 2015. Abiotic and biotic processes governing the fate of phenylurea herbicides in soils: a review. Crit. Rev. Environ. Sci. Technol. 45, 1947-1998.

Hussain, S., Sorensen, S.R., Devers-Lamrani, M., El-Sebai, T., Martin-Laurent, F., 2009. Characterization of an isoproturon mineralizing bacterial culture enriched from a French agricultural soil. Chemosphere 77, 1052-1059.

ISO 10381-1 and -2, 2002. Soil quality - sampling - part 1: guidance on the design of sampling programmes. Part 2: Guidance on Sampling Techniques,

Jin, H., Webster, G.R.B., 1997. Dissipation of chlorpyrifos, oxon and 3,5,6-tricholor-2pyridinol in litter and elm forest soil. J. Environ Sci. Health Part B 32, 879-900.

Johannesen, H., Sørensen, S.R., Aamand, J., 2003. Mineralization of soil-aged isoproturon and isoproturon metabolites by Sphingomonas sp. strain SRS2. J. Environ. Qual. 32, $1250-1257$.

John, E.M., Shaike, J.M., 2015. Chlorpyrifos: pollution and remediation. Environ. Chem. Lett. 13, 269-291.

Joseph, S.V., Zarate, J., 2015. Comparing efficacy of insecticides against cabbage maggot (Diptera: Anthomyiidae) in the laboratory. Crop. Prot. 77, 148-156.

Juhler, R.K., Sørensen, S.R., Larsen, L., 2001. Analysing transformation products of herbicide residues in environmental samples. Water Res. 35, 1371-1378.

Karpouzas, D.G., Kandeler, E., Bru, D., Friedel, I., Auer, Y., Kramer, S., Vasileiadis, S., Petric, I., Udikovic-Kolic, N., Djuric, S., Martin-Laurent, F., 2014. A tiered assessment approach based on standardized methods to estimate the impact of nicosulfuron on the abundance and function of the soil microbial community. Soil Biol. Biochem. 75, 282-291.

Keinath, A.P., 2015. Baseline sensitivity of Didymella bryoniae to cyprodinil and fludioxonil and field efficacy of these fungicides against isolates resistant to pyraclostrobin and boscalid. Plant Dis. 99, 815-822.

Laabs, V., Amelung, W., Fent, G., Zech, W., Kubiak, R., 2002. Fate of ${ }^{14} \mathrm{C}$-labeled soybean and corn pesticides in tropical soils of Brazil under laboratory conditions. J. Agric. Food Chem. 50, 4619-4627.

Laabs, V., Amelung, W., Pinto, A., Altstaedt, A., Zech, W., 2000. Leaching and degradation of corn and soybean pesticides in anoxisol of the Brazilian Cerrados. Chemosphere 41, $1441-1449$.

Lehr, S., Scheunert, I., Beese, F., 1996. Mineralization of free and cell-wall-bound isoproturon in soils in relation to soil microbial from environmental pollutants. Soil Biol. Biochem. 28, 1-8.

Li, Y., Dong, F., Liu, X., Xu, J., Han, Y., Zheng, Y., 2015. Enantioselectivity in tebuconazole and myclobutanil non-target toxicity and degradation in soils. Chemosphere 122, 145-153.

Martin-Laurent, F., Kandeler, E., Pertic, I., Djuric, S., Karpouzas, D.G., 2013. ECOFUNMICROBIODIV: an FP7 European project for developing and evaluating innovative tools for assessing the impact of pesticides on soil functional microbial diversity-towards new pesticide registration regulation? Environ. Sci. Pollut. Res. 20, 1203-1205.

Mudd, P.J., Hance, R.J., Wright, S.J.L., 1983. The persistence and metabolism of isoproturon in soil. Weed Res. 23, 239-347.

Muñoz-Leoz, B., Ruiz-Romera, E., Antigüedad, I., Garbisu, C., 2011. Tebuconazole application decreases soil microbial biomass and activity. Soil Biol. Biochem. 43, 2176-2183.

OECD, 2000. OECD guidelines for the testing of chemicals. Adsorption - Desorption Using a Batch Equilibrium Method. 
Papadopoulou, E.S., Lagos, S., Spentza, F., Vidiadakis, E., Karas, P.A., Klitsinaris, T. Karpouzas, D.G., 2016. The dissipation of fipronil, chlorpyrifos, fosthiazate and ethoprophos in soils from potato monoculture areas: first evidence for the enhanced biodegradation of fosthiazate. Pest Manag. Sci. 72, 1040-1050.

Potter, T.L., Strickland, T.C., Joo, H., Culbreath, A.K., 2005. Accelerated soil dissipation of tebuconazole following multiple applications to peanut. J. Environ. Qual. 34, 1205-1213.

Racke, K.D., 1993. Environmental fate of chlorpyrifos. Rev. Environ. Contam. Toxicol. 131, $1-150$.

Racke, K.D., Laskowski, D.A., Schultz, M.R., 1990. Resistance of chlorpyrifos to enhanced biodegradation in soil. J. Agric. Food Chem. 38, 1430-1436.

Racke, K.D., Steele, K.P., Yoder, R.N., Dick, W.A., Avidov, E., 1996. Factors effecting the hydrolytic degradation of chlorpyrifos in soil. J. Agric. Food Chem. 44, 1582-1592.

Rodríguez-Cruz, M.S., Jones, J.E., Bending, G.D., 2006. Field-scale study of the variability in pesticide biodegradation with soil depth and its relationship with soil characteristics. Soil Biol. Biochem. 38, 2910-2918.

Sancez-Gonzalez, S., Pose-Juan, E., Herrero-Hernandez, E., Alvarez-Martin, A., SancezMartin, M.J., Rodriguez-Cruz, S., 2013. Pesticide residues in groundwaters and soils of agricultural areas in the Águeda River Basin from Spain and Portugal. Int. J. Environ. Anal. Chem. 93, 1585-1601.

Singh, B.K., Walker, A., Alun, J., Morgan, W., Wright, D.J., 2003. Effects of soil pH on the biodegradation of chlorpyrifos and isolation of a chlorpyrifos-degrading bacterium. Appl. Environ. Microbiol. 69, 5198-5206.

Skark, C., Zullei-Seibert, N., 1995. The occurrence of pesticides in groundwater - results of case studies. Int. J. Environ. Anal. Chem. 58, 387-396.

Skark, C., Zullei-Seibert, N., Willme, U., Gatzemann, U., Schlett, C., 2004. Contribution of non-agricultural pesticides to pesticide load in surface water. Pest Manag. Sci. 60, 525-530.
Sørensen, S.R., Aamand, J., 2001. Biodegradation of the phenylurea herbicide isoproturon and its metabolites in agricultural soils. Biodegradation 12, 69-77.

Sørensen, S.R., Ronen, Z., Aamand, J., 2001. Isolation from agricultural soil and characterization of a Sphingomonas sp. able to mineralize the phenylurea herbicide isoproturon. Appl. Environ. Microbiol. 67, 5403-5409.

Storck, V., Lucini, L., Mamy, L., Ferrari, F., Papadopoulou, E.S., Nikolaki, S., Karas, P.A., Servien, R., Karpouzas, D.G., Trevisan, M., Benoit, P., Martin-Laurent, F., 2016. Identification and characterization of tebuconazole transformation products in soil by combining suspect screening and molecular typology. Environ. Pollut. 208, 537-545.

Strickland, T.C., Potter, T.L., Joo, H., 2004. Tebuconazole dissipation and metabolism in Tifton loamy sand during laboratory incubation. Pest Manag. Sci. 60, 703-709.

Teng, H., Chien-To, H., 1998. Influence of surface characteristics on liquid phase adsorption of phenol by activated carbon prepared from Bituminons coal. Ind. Eng. Chem. Res. 37, 3168-3624.

Tixier, C., Sancelme, M. Aït-Aïssa, S., Widehem, P., Bonnemoy, F, Cuer, A., Truffaut, N. Veschambre, H., 2002. Biotransformation of phenylurea herbicides by a soil bacterial strain, Arthrobacter sp. structure, ecotoxicity and fate of diuron metabolite with soil fungi. Chemosphere 46, 519-526.

Walker, A., Jurado-Exposito, M., Bending, G.D., Smith, V.J.R., 2001. Spatial variability in the degradation rate of isoproturon in soil. Environ. Pollut. 111, 407-415.

Wang, C., Wang, F., Zhang, Q., Liang, W., 2016. Individual and combined effects of tebuconazole and carbendazim on soil microbial activity. Eur. J. Soil Biol. 72, 6-13.

Wang, Y., Wang, C., Gao, J., Liu, C., Cui, L., Li, A., 2015. Dissipation, residues, and safety evaluation of trifloxystrobin and tebuconazole on ginseng and soil. Environ. Monit. Assess. 187, 344-356. 